\title{
Solid-phase molecular recognition of cytosine based on proton-transfer reaction. Part II. supramolecular architecture in the cocrystals of cytosine and its 5-Fluoroderivative with 5-Nitrouracil
}

\author{
Gustavo Portalone
}

\begin{abstract}
Background: Cytosine is a biologically important compound owing to its natural occurrence as a component of nucleic acids. Cytosine plays a crucial role in DNA/RNA base pairing, through several hydrogen-bonding patterns, and controls the essential features of life as it is involved in genetic codon of 17 amino acids. The molecular recognition among cytosines, and the molecular heterosynthons of molecular salts fabricated through protontransfer reactions, might be used to investigate the theoretical sites of cytosine-specific DNA-binding proteins and the design for molecular imprint.

Results: Reaction of cytosine (Cyt) and 5-fluorocytosine (5Fcyt) with 5-nitrouracil (Nit) in aqueous solution yielded two new products, which have been characterized by single-crystal $X$-ray diffraction. The products include a dihydrated molecular salt (CytNit) having both ionic and neutral hydrogen-bonded species, and a dihydrated cocrystal of neutral species (5FcytNit). In CytNit a protonated and an unprotonated cytosine form a triply hydrogen-bonded aggregate in a self-recognition ion-pair complex, and this dimer is then hydrogen bonded to one neutral and one anionic 5-nitrouracil molecule. In 5FcytNit the two neutral nucleobase derivatives are hydrogen bonded in pairs. In both structures conventional $\mathrm{N}-\mathrm{H} \cdots \mathrm{O}, \mathrm{O}-\mathrm{H} \cdots \mathrm{O}, \mathrm{N}-\mathrm{H}^{+\cdots} \mathrm{N}$ and $\mathrm{N}-\mathrm{H}^{\prime \cdots} \mathrm{N}^{-}$intermolecular interactions are most significant in the structural assembly.

Conclusion: The supramolecular structure of the molecular adducts formed by cytosine and 5-fluorocytosine with 5-nitrouracil, CytNit and 5FcytNit, respectively, have been investigated in detail. CytNit and 5FcytNit exhibit widely differing hydrogen-bonding patterns, though both possess layered structures. The crystal structures of CytNit (Dpka $=-0.7$, molecular salt) and 5FcytNit (Dpk $=-2.0$, cocrystal) confirm that, at the present level of knowledge about the nature of proton-transfer process, there is not a strict correlation between the Dpk $\mathrm{k}_{\mathrm{a}}$ values and the proton transfer, in that the acid/base $p k_{a}$ strength is not a definite guide to predict the location of $\mathrm{H}$ atoms in the solid state. Eventually, the absence in 5FcytNit of hydrogen bonds involving fluorine is in agreement with findings that covalently bound fluorine hardly ever acts as acceptor for available Brønsted acidic sites in the presence of competing heteroatom acceptors.
\end{abstract}

\section{Background}

Our more recent knowledge of both the detail and the variety of DNA structures themselves, and the manner in which they are recognized by regulatory proteins, mutational compounds and drugs, is starting to pave the

Correspondence: g.portalone@caspur.it

Department of Chemistry, "Sapienza" University of Rome, P.le A. Moro 5, Rome I-00185, Italy way to more profound levels of understanding of the process of gene regulation, mutation/carcinogenesis, and drug action at molecular level. However, despite improvements in the average resolution of crystal structures, there is a need to clarify structural details for better understanding of structure-function and structurestability relationships. The underlying relationships between DNA sequences, structure and flexibility is only partially understood, owing to the delicate nature of a 
number of competing weak forces. Therefore, there is a great interest for the interaction of both small molecules and proteins with DNA as well as for the function of resulting complexes.

Among several non-covalent binding interactions (i.e. hydrogen bonding, ionic interactions, van der Waals and $\pi-\pi$ stacking), hydrogen bonding is very commonly used by chemists for the de novo design of self-assembled or self-associated compounds, because of its strength and directional properties $[1,2]$. This is especially true for biological structures, and in the last decade in this Laboratory considerable efforts have been addressed on designing assemblies of nucleic acid bases with aromatic $\mathrm{N}$-heterocycles in the solid state to mimic, via multiple hydrogen bonds, the base-pairing of nucleic acids. The results of these investigations have led to a number of structural studies [3-15].

As hydrogen bonds may be considered the partially activated precursors to proton-transfer reactions [16], whenever the hydrogen-bonding associations result in complete proton transfer an ionic compound is produced, and the non-covalent interactions between hydrogen-bonding groups are reinforced. The relevance of proton transfer in DNA/RNA systems was raised many years ago. A few years after Watson and Crick's suggestion that the genetic code may be perturbed by the formation of nucleic acid bases (NABs) in so-called rare (not canonical keto-amine) tautomers [17], in a pioneering work Lowdin introduced the hypothesis that rare tautomeric forms could be produced in pairs by intermolecular single/double proton transfer (SPT/DPT) reactions in DNA within the hydrogen bonds connecting a base pair [18]. If, during the replication of DNA, instead of normal combinations of complementary NABs other combinations are possible, the normal hydrogen-bonding pattern in DNA is altered and the sequence of bases in recovered DNA is different and leads to spontaneous mutations. Many theoretical studies have been devoted to check Lowdin's hypotheses $[19,20]$. At present, for neutral systems all studies agree that the SPT reaction is less favorable than the DPT one, as the single transfer process implies a charge separation when forming the ion-pair complex, while in the DPT process the electroneutrality is retained. Nevertheless, the energy barrier is high, and the double tautomer is thermodynamically unstable. Thus, DPT reaction is not expected to have mutagenic effects. In contrast to this, for the protonated base pairs the SPT products are largely stabilized, since the SPT reaction does not imply the creation of an ion pair but just the transfer of a positive charge. Products arising from such processes are stable and can be involved in mutagenic phenomena. Protonation of NABs also contributes to stabilization of unusual DNA structures like triple helix, which is greatly stabilized at acidic $\mathrm{pH}$, and knowledge about attachment of the proton is essential for the design of new intercalating drugs that stabilize the triple helix [21].

Among the four DNA bases, cytosine (Cyt) has been the focus of much research along these lines, as it plays a crucial role in DNA/RNA base pairing, through several hydrogen-bonding patterns, and controls the essential features of life as it is involved in genetic codon of 17 amino acids. Moreover, protonation at N3 of the cytosine ring (according to the numbering scheme given in Figure 1) is a necessary step in homo-base pairs association. A well-known example is the $i$-motif, based on the formation of quadruplex structure involving Cyt-Cyt $\mathrm{H}^{+}$ reversed mismatch pairs for polyCyt at acidic $\mathrm{pH}$ [22]. In this respect, the supramolecular structure of cytosine coupled with uracil acidic derivatives can be regarded as a model in the solid phase of molecular recognition based on proton-transfer reactions.

A possible guide for the synthesis of neutral or charged components in hydrogen-bonded molecular adducts formed through the transfer of a proton can be the $\mathrm{D} p \mathrm{k}_{\mathrm{a}}\left[p \mathrm{k}_{\mathrm{a}}\right.$ (conjugate acid of the base) $-p \mathrm{k}_{\mathrm{a}}$ (acid), $p \mathrm{k}_{\mathrm{a}}$ 's are for aqueous solution at $25^{\circ} \mathrm{C}$ ] [23]. It is generally accepted that for large $\mathrm{D} p \mathrm{k}_{\mathrm{a}}$ (i.e. greater than 3) salts of the type $\mathrm{B}^{+}-\mathrm{H}^{\cdots} \mathrm{A}^{-}$are formed. Smaller $\mathrm{D} p \mathrm{k}_{\mathrm{a}}$ (less than 0 ) will almost exclusively result in neutral component $\mathrm{B} \cdots \mathrm{H}$-A compounds (cocrystal), but that parameter seems inappropriate for accurately predicting salt or cocrystal formation in the solid state when $\mathrm{D} p \mathrm{k}_{\mathrm{a}}$ is between 0 and $3[24,25]$. The proton-transfer process can be improved through the use of stronger Brønsted acids and/or bases, and indeed cytosine $\left(p \mathrm{k}_{\mathrm{a} 1}=4.6\right.$ and $p \mathrm{k}_{\mathrm{a} 2}=12.2$, [26]) is readily protonated at the N3 position in the presence of strong acids. Even though this molecule is particularly amenable to the formation of molecular complexes from proton-transfer reactions, the first example of solid-state molecular recognition of cytosine by acidic nucleobase derivatives has appeared only recently [27].

Replacement of hydrogen or hydroxyl group by fluorine in a bioactive compound often imparts, or improves, desirable biochemical and/or pharmacological properties (i.e. 5-fluorouracil). Fluorination is commonly regarded as an isosteric monovalent substitution, since the van der Waal's radii are $1.20 \AA$ for $\mathrm{H}, 1.40 \AA$ for $\mathrm{OH}$ and $1.47 \AA$ for $F$ [28]. Thus, a monofluorinated analogue is geometrically very similar to its parent molecule and hence meets the steric requirements at enzyme receptor sites [29-33]. The effect of fluorine as a substituent in biomolecules can be attributed to the strong electronwithdrawing properties (and on electron pair donating mesomeric effect in conjugated systems). It should be noted that the ability of C-F groups to act as a weak 


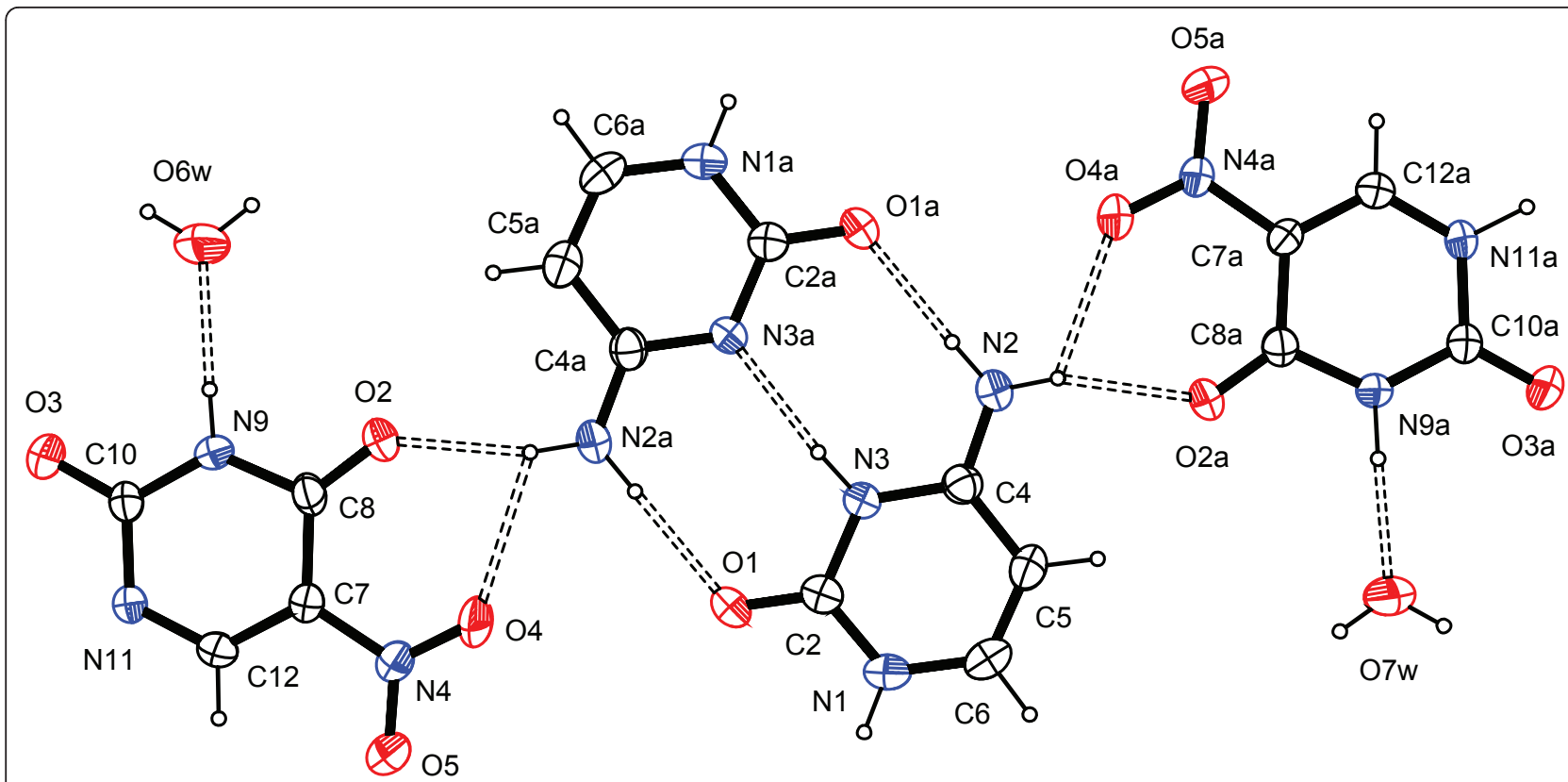

Figure 1 The asymmetric unit of CytNit, showing the atom-labeling scheme and hydrogen bonding (double dashed lines). Displacements ellipsoids are drawn at 50\% probability level and $\mathrm{H}$ atoms as small spheres of arbitrary size.

hydrogen bond acceptors (1-3 vs $5-10 \mathrm{kcal} / \mathrm{mol}$ for oxygen as an acceptor) turned out to be the most discussed (and controversial) issue for organic fluorine in literature [34-38]. Since, as anticipated, hydrogen bonds are indispensable features in higher-ordered DNA/RNA structures, this hard-argued aspect increases the value of fluoro-modified nucleobases in molecular recognition.

In this context, CytNit and 5FcytNit [(I) and (II) in Figure 2, respectively] have been synthesized by a<smiles>Nc1cc[nH]c(=O)n1</smiles>

(I)<smiles>Nc1nc(=O)[nH]cc1F</smiles><smiles>O=c1[nH]cc([N+](=O)[O-])c(=O)[nH]1</smiles>

$2 \mathrm{H}_{2} \mathrm{O}$

(II)

Figure 2 The schematic diagram for CytNit, (I), and 5FcytNit, (II), respectively. reaction between cytosine (4-amino-2-hydroxypyrimidine, Cyt) and 5-fluorocytosine (4-amino-5-fluoro-2hydroxypyrimidine, 5Fcyt) and 5-nitrouracil (5-nitro-2,4dihydroxypyrimidine, Nit) as part of ongoing interest in supramolecular architectures of biologically important proton-transfer compounds. In situations where both anions and cations are derived from organic acids and bases, the term molecular salts have been proposed [39].

\section{Results and discussion}

The asymmetric unit of molecular salt (I) is shown in Figure 1 and consists of one protonated $(\mathrm{CytH}+)$ and one neutral cytosine (Cyt) aminooxo tautomers, coplanar with one neutral (Nit) and one anionic $\left(\mathrm{Nit}^{-}\right)$diketo tautomers of 5 -nitrouracil, linked by multiple hydrogen bonds in a plane along with two water molecules of crystallization. A complete deprotonation occurs as a result of the proton-transfer process from N11, the more acidic of the two sites available for ionization in the heterocyclic ring of Nit [13], to the N3 atom of the pyrimidine ring of Cyt. The $\mathrm{H}$ atom at the $\mathrm{N} 3$ position in CytNit was located in difference Fourier maps and is probably not entirely located at the nitrogen site. The unusual displacement parameter, 0.12 (2) $\AA^{2}$, of H3 suggested to investigate a model in which the hydrogen atom is disordered between two positions in the central N3-H3 'N3a hydrogen bond. Attempts in the current work to quantify the hydrogen atom disorder directly from the refinement of the hydrogen atom site occupancy factors (SOFs) from the X-ray diffraction data 
proved to be somewhat problematic. Indeed, bonding effects and correlation of SOFs with thermal parameters make the obtained hydrogen atom occupancies less reliable. A refinement strategy was adopted that fixed the isotropic thermal factors (ITFs) of the disordered hydrogen atoms sites to be equal to the average of the other hydrogen atom ITFs. This model produced unstable refinements. A neutron diffraction study would be needed to make any further observations about the behavior of this hydrogen atom.

The N3 protonation or its absence reflects in the C2N3-C4 bond angle. The N3 protonation in $\mathrm{CytH}+$ is consistent with the larger C2-N3-C4 bond angle, 122.5 $(3)^{\circ}$, while for unprotonated Cyt the angle is $121.1(3)^{\circ}$. Nevertheless the latter value, when compared with the corresponding one reported for cytosine, 119.4(2) ${ }^{\circ}$ [40], could suggest again that $\mathrm{H} 3$ is partly shared in the structure. The prevailing protonation site is further corroborated by a general comparison of the molecular geometry of the base ring of $\mathrm{CytH}+$ in the molecular adduct (Table 1) with that observed in a number of structures with protonated cytosine [27]. Minor exceptions can be attributed to the different hydrogen

Table 1 Selected bond lengths (Å) and angles $\left(^{\circ}\right)$ for CytNit and 5FcytNit

\begin{tabular}{|c|c|c|c|}
\hline & \multicolumn{2}{|c|}{ CytNit } & \multirow{2}{*}{$\begin{array}{l}\text { 5FcytNit } \\
\mathrm{a}=\text { nil }\end{array}$} \\
\hline & $\mathrm{a}=\mathrm{nil}$ & $a=a$ & \\
\hline \multicolumn{4}{|l|}{ 5-Nitrouracil } \\
\hline $\mathrm{O} 2 \mathrm{a}-\mathrm{C} 8 \mathrm{a}$ & $1.217(4)$ & $1.211(4)$ & $1.221(8)$ \\
\hline O3a-C10a & 1.235 (4) & $1.225(4)$ & 1.201 (8) \\
\hline $\mathrm{O} 4 \mathrm{a}-\mathrm{N} 4 \mathrm{a}$ & $1.211(3)$ & $1.218(4)$ & $1.208(7)$ \\
\hline O5a-N4a & $1.241(4)$ & $1.220(3)$ & $1.219(7)$ \\
\hline $\mathrm{N} 4 \mathrm{a}-\mathrm{C} 7 \mathrm{a}$ & $1.418(4)$ & $1.437(4)$ & $1.430(8)$ \\
\hline $\mathrm{C} 7 \mathrm{a}-\mathrm{C} 12 \mathrm{a}$ & $1.371(4)$ & $1.361(4)$ & $1.371(8)$ \\
\hline C7a-C8a & $1.452(5)$ & $1.462(4)$ & $1.448(8)$ \\
\hline $\mathrm{C} 8 \mathrm{a}-\mathrm{N9a}$ & $1.390(4)$ & $1.387(4)$ & 1.369 (8) \\
\hline N9a-C10a & $1.364(4)$ & $1.362(4)$ & $1.371(9)$ \\
\hline C10a-N11a & $1.373(4)$ & $1.383(4)$ & $1.382(9)$ \\
\hline $\mathrm{N} 11 \mathrm{a}-\mathrm{C} 12 \mathrm{a}$ & $1.324(4)$ & $1.324(4)$ & $1.314(9)$ \\
\hline $\mathrm{C} 10 \mathrm{a}-\mathrm{N} 11 \mathrm{a}-\mathrm{C} 12 \mathrm{a}$ & $118.7(3)$ & $121.7(3)$ & $123.1(5)$ \\
\hline \multicolumn{4}{|l|}{ Cytosine } \\
\hline F1-C5 & & & $1.347(7)$ \\
\hline $\mathrm{O} 1 \mathrm{a}-\mathrm{C} 2 \mathrm{a}$ & $1.232(4)$ & $1.241(4)$ & $1.252(8)$ \\
\hline $\mathrm{N} 2 \mathrm{a}-\mathrm{C} 4 \mathrm{a}$ & $1.320(4)$ & $1.317(4)$ & $1.314(9)$ \\
\hline N1a-C6a & $1.356(4)$ & $1.362(4)$ & $1.362(8)$ \\
\hline $\mathrm{N} 1 \mathrm{a}-\mathrm{C} 2 \mathrm{a}$ & $1.357(4)$ & $1.375(4)$ & $1.358(8)$ \\
\hline $\mathrm{C} 2 \mathrm{a}-\mathrm{N3} \mathrm{a}$ & $1.367(4)$ & $1.357(4)$ & $1.340(9)$ \\
\hline $\mathrm{N} 3 \mathrm{a}-\mathrm{C} 4 \mathrm{a}$ & $1.355(4)$ & $1.350(4)$ & $1.343(8)$ \\
\hline$C 4 a-C 5 a$ & $1.417(4)$ & $1.427(5)$ & $1.421(9)$ \\
\hline C5a-C6a & $1.336(5)$ & $1.328(5)$ & 1.319 (9) \\
\hline $\mathrm{C} 2 \mathrm{a}-\mathrm{N} 3 \mathrm{a}-\mathrm{C} 4 \mathrm{a}$ & $122.5(3)$ & $121.1(3)$ & $120.6(5)$ \\
\hline
\end{tabular}

bonding configurations. Concerning molecular dimensions of the 5-nitrouracilate anion, bond lengths and bond angles of the heteroaromatic ring are in accord with values obtained for $\mathrm{Nit}^{-}$in the (1:1) benzamidinium 5-nitrouracilate adduct [14]. The two uracil derivatives are coplanar, as in Nit and in $\mathrm{Nit}^{-}$the nitro groups form dihedral angle of $1.4(1)^{\circ}$ and $1.1(1)^{\circ}$ with the mean plane of the pyrimidine rings.

In the supramolecular structure of molecular salt (I), the hydrogen-bonding scheme is rather complex, and is characterized by sixteen unique two- and three-center intermolecular hydrogen bonds, namely ten $\mathrm{N}-\mathrm{H}^{\cdots} \mathrm{O}$, one $\mathrm{N}-\mathrm{H}^{+\cdots} \mathrm{N}$, one $\mathrm{N}-\mathrm{H}^{\cdots} \mathrm{N}^{-}$and four $\mathrm{Ow}-\mathrm{H}^{\cdots \cdots} \mathrm{O}$ bonds (Table 2). For descriptive purposes, it is convenient to select a 'superadduct' consisting of one asymmetric unit and then analyze firstly the hydrogen bonding within this aggregate, and secondly the hydrogen-bonding patterns between neighboring individual superadducts (Figure 3).

As previously mentioned, in the crystal structure of CytNit each asymmetric unit comprises four molecules

Table 2 Hydrogen bonding geometry for CytNit and 5FcytNit

\begin{tabular}{|c|c|c|c|c|}
\hline$D-\mathrm{H} \cdots A$ & $D-\mathrm{H}(\AA ̊)$ & $H \cdots A(\AA)$ & $D \ldots A(\AA ̊)$ & $D-\mathrm{H} \cdots A\left({ }^{\circ}\right)$ \\
\hline \multicolumn{5}{|l|}{$\overline{C y t N i t}$} \\
\hline $\mathrm{N} 1-\mathrm{H} 1 \ldots \mathrm{O} 3 \mathrm{a}^{\mathrm{i}}$ & $0.94(5)$ & $1.88(5)$ & $2.780(4)$ & $161(4)$ \\
\hline $\mathrm{N} 2-\mathrm{H} 2 \mathrm{a} \cdots \mathrm{OO} 1 \mathrm{a}$ & $0.95(4)$ & $1.89(4)$ & $2.830(4)$ & $172(3)$ \\
\hline $\mathrm{N} 2-\mathrm{H} 2 \mathrm{~b} \cdots \mathrm{O} 2 \mathrm{a}$ & $0.96(3)$ & $1.92(3)$ & $2.848(3)$ & $164(3)$ \\
\hline $\mathrm{N} 2-\mathrm{H} 2 \mathrm{~b} \cdots \mathrm{O} 4 \mathrm{a}$ & $0.96(3)$ & $2.29(3)$ & $2.829(4)$ & $115(3)$ \\
\hline $\mathrm{N} 3-\mathrm{H} 3+\cdots \mathrm{N} 3 \mathrm{a}$ & $0.99(5)$ & $1.85(5)$ & $2.837(3)$ & $175(2)$ \\
\hline N9-H9...O6w & $0.84(3)$ & $1.96(3)$ & $2.795(4)$ & $175(3)$ \\
\hline N1a-H1a $\cdots 3^{\mathrm{ii}}$ & $0.95(4)$ & $1.88(5)$ & $2.790(4)$ & $157(4)$ \\
\hline $\mathrm{N} 2 \mathrm{a}-\mathrm{H} 21 \mathrm{a} \cdots \mathrm{O} 1$ & $0.93(4)$ & $1.96(4)$ & $2.876(4)$ & $171(3)$ \\
\hline $\mathrm{N} 2 \mathrm{a}-\mathrm{H} 21 \mathrm{~b} \cdots \mathrm{O} 2$ & $0.89(3)$ & $1.96(3)$ & $2.830(4)$ & $165(3)$ \\
\hline $\mathrm{N} 2 \mathrm{a}-\mathrm{H} 21 \mathrm{~b} \cdots \mathrm{O} 4$ & $0.89(3)$ & $2.36(3)$ & $2.869(4)$ & $117(2)$ \\
\hline N9a-H9a...O7w & $1.00(4)$ & $1.75(4)$ & $2.744(4)$ & $176(4)$ \\
\hline N11a-H11aa..N1 1iii & $0.99(3)$ & $1.70(4)$ & $2.686(3)$ & $176(3)$ \\
\hline $\mathrm{O} 6 \mathrm{w}-\mathrm{H} 61 \ldots \mathrm{O} 1 \mathrm{a}^{\mathrm{iv}}$ & $0.84(5)$ & $2.02(5)$ & $2.858(4)$ & $171(5)$ \\
\hline O6w-H62...O5a & $0.85(5)$ & $2.43(5)$ & $3.271(4)$ & $170(5)$ \\
\hline $\mathrm{O} 7 \mathrm{~W}-\mathrm{H} 71 \ldots \mathrm{O} 1^{v}$ & $0.86(5)$ & $2.02(5)$ & $2.878(4)$ & $175(5)$ \\
\hline $\mathrm{O} 7 \mathrm{w}-\mathrm{H} 72 \cdots \mathrm{O}^{\vee}$ & $0.80(5)$ & $2.41(5)$ & $3.199(4)$ & $168(6)$ \\
\hline \multicolumn{5}{|l|}{ 5FcytNit } \\
\hline $\mathrm{N} 11-\mathrm{H} 11 \ldots \mathrm{N} 3$ & $1.00(6)$ & $1.80(6)$ & $2.763(7)$ & $162(5)$ \\
\hline $\mathrm{N} 9-\mathrm{H} 9 \cdots \mathrm{O}^{\mathrm{vi}}$ & $0.88(8)$ & $1.80(8)$ & $2.670(7)$ & $174(7)$ \\
\hline $\mathrm{N} 2-\mathrm{H} 2 \mathrm{a} \cdots \mathrm{O} 3$ & $0.87(8)$ & $2.27(8)$ & $3.104(7)$ & $161(8)$ \\
\hline $\mathrm{N} 2-\mathrm{H} 2 \mathrm{~b} \cdots \mathrm{O} 7 \mathrm{w}$ & $0.71(9)$ & $2.27(9)$ & $2.964(9)$ & $167(10)$ \\
\hline $\mathrm{N} 1-\mathrm{H} 1 \ldots 2^{\mathrm{vii}}$ & $0.86(7)$ & $2.03(7)$ & $2.881(7)$ & $171(5)$ \\
\hline $\mathrm{O} 6 \mathrm{w}-\mathrm{H} 6 \mathrm{a} \cdots \mathrm{O} 2$ & $0.89(2)$ & $1.93(4)$ & $2.801(7)$ & 167 (14) \\
\hline O6w-H6b...O6w viii & $0.89(2)$ & $1.92(8)$ & $2.723(5)$ & $151(14)$ \\
\hline $\mathrm{O} 7 \mathrm{w}-\mathrm{H} 7 \mathrm{a} \cdots \mathrm{O} 7 \mathrm{w}^{\mathrm{ix}}$ & $0.89(2)$ & 2.07 (4) & $2.935(9)$ & $164(12)$ \\
\hline $\mathrm{O} 7 \mathrm{w}-\mathrm{H} 7 \mathrm{~b} \cdot \mathrm{O} \mathrm{O} 6 \mathrm{w}^{x}$ & $0.88(2)$ & $2.33(4)$ & $3.189(12)$ & $166(12)$ \\
\hline
\end{tabular}

Symmetry code(s): (i) $x,-y-1 / 2, z-1 / 2$; (ii) $x,-y+1 / 2, z+1 / 2$; (iii) $x, y, z+1$; (iv) $x,-y$ $+1 / 2, z-1 / 2$; (v) $x,-y-1 / 2, z+1 / 2$; (vi) $x-1 / 2,-y+1 / 2, z-3 / 2$; (vii) $x+1 / 2,-y+1 / 2, z+3 /$ 2 ; (viii) $x,-y, z+1 / 2$; (ix) $x,-y+1, z-1 / 2$; (x) $x-1 / 2,-y+1 / 2, z-1 / 2$. 


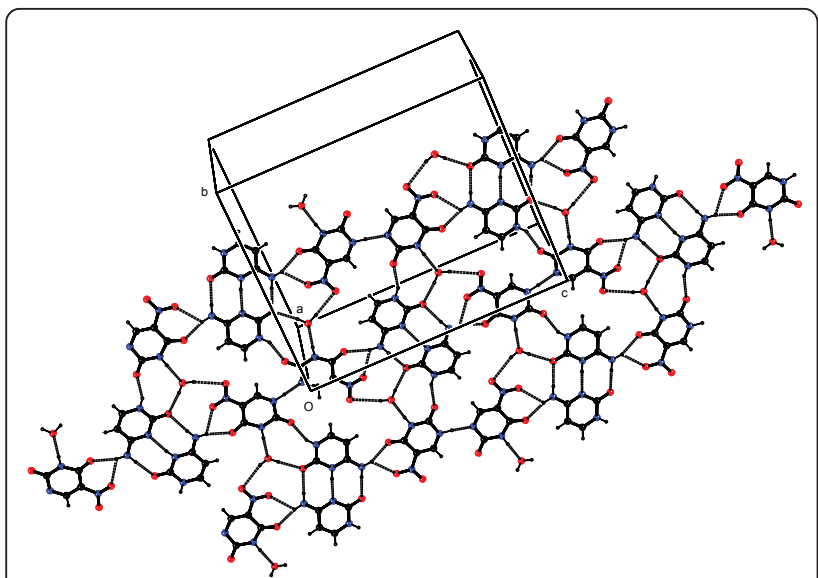

Figure 3 Part of the crystal structure of CytNit, viewed perpendicular to the (100) plane. Displacements ellipsoids are drawn at 50\% probability level and $\mathrm{H}$ atoms as small spheres of arbitrary size. Hydrogen bonds are indicated by double dashed lines.

linked by multiple hydrogen bonds, and two water molecules. In such superadduct one cytosine molecule forms a cation $\left(\mathrm{CytH}^{+}\right)$as a result of the incorporation of an $\mathrm{H}$ atom from one 5-nitrouracil molecule $\left(\mathrm{Nit}^{-}\right)$. Molecules of $\mathrm{CytH}^{+}$are connected to Cyt molecules in dimers via $\mathrm{N}-\mathrm{H}^{\cdots \cdots} \mathrm{O}$ and $\mathrm{N}-\mathrm{H}^{+\cdots} \mathrm{N}$ triple intermolecular hydrogen bonds, forming two adjoining hydrogenbonded rings with graph-set motif $\mathrm{R}_{2}^{2}(8)$. Asymmetric reversed Watson-Crick base pairing occurs via triple hydrogen bonds between the N3 protonated and the neutral cytosine molecule. $\mathrm{Nit}^{-}$and Nit molecules are then connected to cytosinium-cytosine base pairs through bifurcated $\mathrm{N}-\mathrm{H} \cdots \mathrm{O}$ hydrogen-bonded rings with graph-set motifs $\mathrm{R}^{2}{ }_{1}(6)$, and link the two solvent molecules through $\mathrm{N}-\mathrm{H} \cdot \mathrm{O}$ O hydrogen bonds. Similar threecenter $\mathrm{N}-\mathrm{H}^{\cdots} \mathrm{O}$ interactions, where one of the oxygen atoms of the nitro group and the adjacent oxygen atom of the ring act as hydrogen-bond acceptors, have been observed in the supramolecular structure of cocrystals of (1:1) nitrouracil/pyridine [41]. N- $\mathrm{H}^{\cdots} \mathrm{N}^{-}$hydrogen bonds then connect adjacent superadducts leading to one-dimensional supramolecular polymeric chains by translation approximately along the $c$ axis. In addition to the previously reported hydrogen bonds, there are a further six distinct interactions, and hydrogen bonds delineate patterns in which rings are the most prominent features. $\mathrm{N}-\mathrm{H}^{\cdots} \mathrm{O}$ and $\mathrm{O}-\mathrm{H}^{\cdots} \mathrm{O}$ intermolecular hydrogen bonds, forming two adjoining hydrogenbonded rings of $\mathrm{R}_{3}^{3}(10)$ and $\mathrm{R}_{4}^{4}(10)$ motifs, connect the one-dimensional polymeric chains, thereby generating a two-dimensional supramolecular hydrogen-bonded network parallel to the $b c$ plane. The formation of this two-dimensional array is facilitated by water molecules, which act as bridges between superadducts.
The asymmetric unit of compound II is shown in Figure 4 and consists of (1:1) double hydrogen-bonded canonical aminooxo and diketo tautomers of 5-fluorocytosine and 5-nitrouracil molecules, respectively, assembled with two water molecules of crystallization to form a dihydrated cocrystal. Indeed, the two nucleobases are in the neutral form as fluorine, being the most electronegative atom, significantly reduces the basicity of close basic groups in the 5-fluorocytosine molecule $\left(p \mathrm{k}_{\mathrm{a} 1}=3.3\right.$ and $\left.p \mathrm{k}_{\mathrm{a} 2}=10.7\right)$.

In 5 FcytNit the two nucleobases are essentially coplanar, as in Nit the nitro group forms dihedral angle of $4.9(4)^{\circ}$ with the mean plane of the pyrimidine ring. The molecular geometry of the two components of the cocrystal (Table 1) largely agrees with the already known solvent-free structure of the two units $[42,43]$.

The crystal structure of compound (II) is shown in Figure 5. 5-fluorocytosine and 5-nitrouracil molecules are associated in the crystal by extensive hydrogen bonding into a three-dimensional network (Table 2). Each of the 5-fluorocytosine molecules of the asymmetric unit alternates with 5-nitrouracil molecules to form $\mathrm{R}_{2}^{2}(8)$ hydrogen-bonded dimers based on $\mathrm{N}-\mathrm{H} \cdots \mathrm{O}$ interactions. These interactions propagate to form ribbons approximately parallel to the $a b$ plane. These ribbons are connected via $\mathrm{O}-\mathrm{H}^{\cdots} \mathrm{O}$ interactions to water molecules which run along the $c$ axis through perpendicular channels formed by surrounding ribbons. Interestingly, $\mathrm{O}$ atoms of the nitro group in 5-nitrouracil are not involved in hydrogen bonding. Another remarkable finding is that in the crystal structure of 5FcytNit the fluorine atom is not engaged in any significant contact relevant to the packing other than one F...F interaction, 2.915(2) ^.

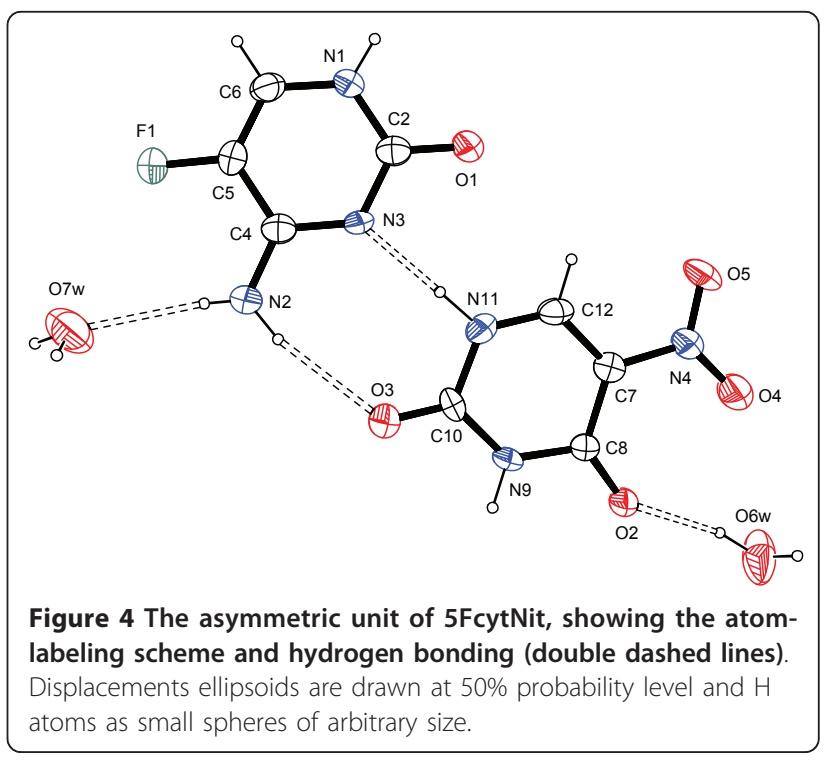




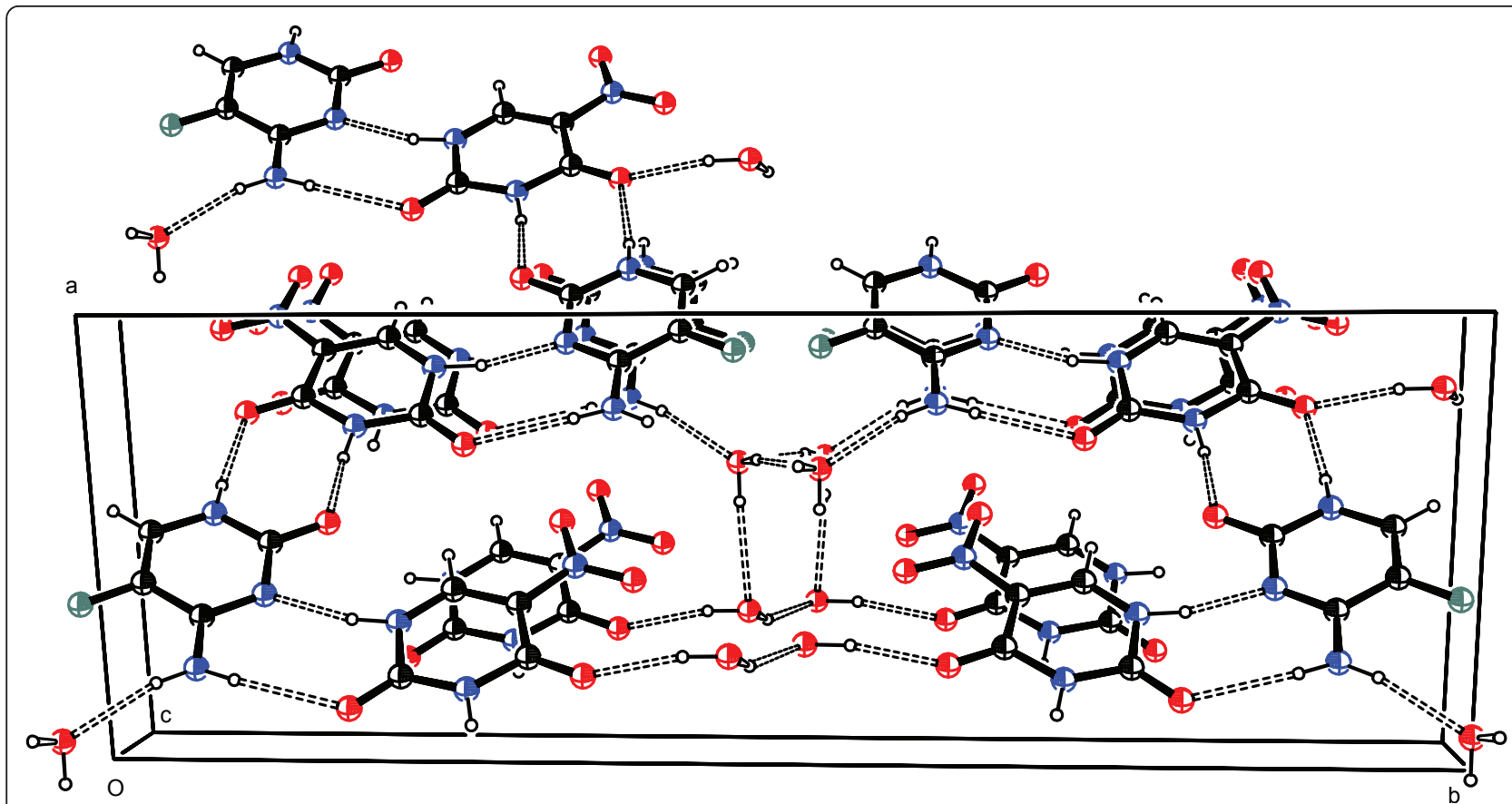

Figure 5 Part of the crystal structure of 5FcytNit, viewed perpendicular to the (001) plane. Displacements ellipsoids are drawn at $50 \%$ probability level and $\mathrm{H}$ atoms as small spheres of arbitrary size. Hydrogen bonds are indicated by double dashed lines.

\section{Conclusion}

The supramolecular structure of the molecular adducts formed by cytosine and 5-fluoro cytosine with 5 -nitrouracil have been investigated in detail. CytNit and 5FcytNit exhibit widely differing hydrogen-bonding patterns, though both possess layered structures. The crystal structures of CytNit $\left(\mathrm{D} p \mathrm{k}_{\mathrm{a}}=-0.7\right.$, molecular salt $)$ and 5 FcytNit $\left(\mathrm{D} p \mathrm{k}_{\mathrm{a}}=-2.0\right.$, co crystal $)$ confirm that, at the present level of knowledge about the nature of protontransfer process, there is not a strict correlation between the $\mathrm{D} p \mathrm{k}_{\mathrm{a}}$ values and the proton transfer, in that the acid/base $p \mathrm{k}_{\mathrm{a}}$ strength is not a definite guide to predict the location of $\mathrm{H}$ atoms in the solid state. Eventually, the absence in 5FcytNit of hydrogen bonds involving fluorine is in agreement with findings that covalently bound fluorine hardly ever acts as acceptor for available Brønsted acidic sites in the presence of competing heteroatom acceptors.

\section{Experimental}

All materials (Aldrich Chemical Company, 99\%) were used as received without further purification. Cytosine and 5-fluorocytosine (1 mmol of each compound) were dissolved in hot water $(15 \mathrm{ml}$ each solution) and added to a $20 \mathrm{ml}$ hot water solution of 5-nitrouracil in equimolar ratio. After concentration to $c a 30 \mathrm{ml}$, the resulting solutions were stirred at $50^{\circ} \mathrm{C}$ for 24 hours under reflux. After two weeks small transparent single crystals were obtained from the slow room-temperature evaporation of the two solutions and then used for Xray diffraction experiments.

\section{$X$-ray Crystallography}

The intensity data were collected on the Oxford Diffraction Xcalibur S CCD diffractometer with graphite-monochromated Mo K $\alpha$ radiation $(\lambda=0.71069 \AA)$ at $298(2) \mathrm{K}$ operated at $50 \mathrm{kV}$ and $40 \mathrm{~mA}$. The data reductions were performed using the CrysAlis software package [44]. Solution, refinement and analysis of the structures were done using the programs integrated in the WinGX system [45]. The structures were solved by direct methods (SIR2002) [46] and refined by the full-matrix least-squares method based on $F^{2}$ (SHELXL-97) [47]. The non-hydrogen atoms were refined anisotropically till convergence was reached. All the hydrogen atoms were located in a difference Fourier map and refined isotropically, with the exception of those hydrogen atoms linked to the $C$-ring atoms, which were positioned with idealized geometry and refined as riding on their parent atom $[\mathrm{C}-\mathrm{H}=0.93 \AA]$; the $\mathrm{U}_{\text {iso }}$ 's $(\mathrm{H})$ were set as 1.2 times the $U_{\text {eq }}$ value of the appropriate carrier atom. At this stage difference Fourier maps showed for both molecular adducts values not exceeding 0.25 (4) e $\AA^{-3}$ which, however, are not of chemical significance. Geometrical calculations were performed using PLATON [48]. The figures were prepared using ORTEP-3 [49]. The final crystallographic data collection and refinement are summarized in Table 3. CCDC reference numbers: 827539 and 827540. All CIF information can be found in Additional file 1 . 
Table 3 Experimental details for CytNit and 5FcytNit

\begin{tabular}{|c|c|c|}
\hline & CytNit & 5Fcytnit \\
\hline Chemical formula & $\begin{array}{l}\mathrm{C}_{4} \mathrm{H}_{5} \mathrm{~N}_{3} \mathrm{O} \cdot \mathrm{C}_{4} \mathrm{H}_{3} \mathrm{~N}_{3} \mathrm{O}_{4} \cdot \\
\mathrm{C}_{4} \mathrm{H}_{6} \mathrm{~N}_{3} \mathrm{O}^{+} \cdot \mathrm{C}_{4} \mathrm{H}_{2} \mathrm{~N}_{3} \mathrm{O}_{4} \cdot 2 \\
\mathrm{H}_{2} \mathrm{O}\end{array}$ & $\begin{array}{l}\mathrm{C}_{4} \mathrm{H}_{4} \mathrm{FN}_{3} \mathrm{O} \\
\mathrm{C}_{4} \mathrm{H}_{3} \mathrm{~N}_{3} \mathrm{O}_{4} \\
2 \mathrm{H}_{2} \mathrm{O}\end{array}$ \\
\hline$M_{\mathrm{r}}$ & 572.44 & 322.23 \\
\hline Crystal system & Orthorhombic & Monoclinic \\
\hline Space group & Pbca & $\mathrm{Cc}$ \\
\hline$a(\AA)$ & $12.7424(9)$ & $10.2066(6)$ \\
\hline$b(\AA)$ & $17.4112(7)$ & $28.2758(11)$ \\
\hline$c(\AA)$ & $21.0833(10)$ & $4.7187(3)$ \\
\hline$\alpha\left({ }^{\circ}\right)$ & 90 & 90 \\
\hline$\beta\left(^{\circ}\right)$ & 90 & $111.293(6)$ \\
\hline$\left.x^{\circ}\right)$ & 90 & 90 \\
\hline$V\left(\AA^{3}\right)$ & $4677.6(4)$ & $1268.85(12)$ \\
\hline Z & 8 & 4 \\
\hline$\lambda(\AA)$ & 0.71069 & 0.71069 \\
\hline$T(\mathrm{~K})$ & $298(2)$ & $298(2)$ \\
\hline$\mu\left(\mathrm{mm}^{-1}\right)$ & 0.14 & 0.16 \\
\hline Crystal size (mm) & $0.15 \times 0.12 \times 0.12$ & $0.15 \times 0.12 \times 0.03$ \\
\hline No. of measured & 13436 & 39739 \\
\hline independent & 4177 & 1246 \\
\hline $\begin{array}{l}\text { observed }[l>2 \sigma()] \\
\text { reflections }\end{array}$ & 2589 & 1230 \\
\hline$R_{\text {int }}$ & 0.041 & 0.050 \\
\hline$R\left[F^{2}>\sigma\left(F^{2}\right)\right]$ & 0.080 & 0.067 \\
\hline$w R\left(F^{2}\right)$ & 0.139 & 0.154 \\
\hline$S$ & 1.16 & 1.47 \\
\hline No. of parameters & 416 & 229 \\
\hline$\Delta \rho_{\max }, \Delta \rho_{\min }\left(\mathrm{e} \AA^{-3}\right)$ & $0.24,-0.19$ & $0.25,-0.28$ \\
\hline
\end{tabular}

\section{Additional material}

Additional file 1: Crystallographic Information. Contains all relevant CIF information.

\section{Competing interests}

The author declares that he has no competing interests.

Received: 1 June 2011 Accepted: 2 September 2011 Published: 2 September 2011

\section{References}

1. Desiraju GR, Krishnamohan Sharma CV: Crystal Engineering and Molecular Recognition. Twin Facets of Supramolecular Chemistry. In The Crystal as a Supramolecular Entity. Edited by: Desiraju GR. Chichester: Wiley and Sons; 1996:31-61.

2. Desiraju GR: Crystal Engineering: A Holistic view. Angew Chem Int Ed Engl 2007, 46:8342-8356.

3. Portalone G, Colapietro M, Ramondo F, Bencivenni L, Pieretti A: The Effect of Hydrogen Bonding on the Structures of Uracil and some Methyl Derivatives by Experiment and Theory. Acta Chem Scand 1999, 53:57-68.

4. Brunetti B, Piacente V, Portalone G: Sublimation Enthalpies of some Methyl Derivatives of Uracil from Vapor Pressures Measurements. J Chem Eng Data 2000, 45:242-246.

5. Brunetti B, Piacente $V$, Portalone G: Sublimation Thermodynamics Parameters for 5-Fluorouracil and its 1-Methyl and 1,3-Dimethyl
Derivatives from Vapor Pressures Measurements. J Chem Eng Data 2002, 47:17-19.

6. Portalone G, Ballirano P, Maras A: The crystal structure of 3-methyluracil from X-ray powder diffraction data. J Mol Struct 2002, 608:35-39.

7. Portalone $\mathrm{G}$, Colapietro M: First example of cocrystals of polymorphic maleic hydrazide. J Chem Crystallogr 2004, 34:609-612.

8. Portalone G, Colapietro M: Redetermination of 5-Fluorocytosine monohydrate. Acta Crystallogr Sect E 2006, 62:01049-01051

9. Portalone $\mathrm{G}$, Colapietro M: Asymmetric base pairing in the complex 5Fluorocytos inium chloride / 5-Fluorocytosine monohydrate. J Chem Crystallogr 2007, 37:141-145.

10. Portalone G, Colapietro M: Redetermination of isocytosine. Acta Crystallogr Sect E 2007, 63:01869-01971.

11. Portalone $\mathrm{G}$, Colapietro $\mathrm{M}$ : The $1: 1$ cocrystals of the proton-transfer compound dilituric acid-phenylbiguanide monohydrate. Acta Crystallogr Sect C 2007, 63:0181-0184.

12. Portalone G, Colapietro M: The 1:1 complex of cytosine and 5-fluorouracil mono hydrate revisited. Acta Crystallogr Sect C 2007, 63:0423-0425.

13. Portalone G, Colapietro M: Unusual syn conformation of 5 -formyluracil stabilized by supramolecular interactions. Acta Crystallogr Sect C 2007, 63: o650-0654.

14. Portalone G: Supramolecular association in proton-transfer adducts containing benzamidinium cations. (I). Four molecular salts with uracil derivatives. Acta Crystallogr Sect C 2010, 66:0295-0301.

15. Portalone G, Irrera S: Supramolecular structure of unnatural nucleobases: revised structure of (2:1) 6-methylisocytosinium dihydrogen monophosphate adduct. J Mol Struct 2011, 991:92-96.

16. Desiraju GR: A Bond by Any Other Name. Angew Chem Int Ed Engl 2011, 50:52-59.

17. Watson JD, Crick FHC: Molecular Structure of Nucleic Acids. Nature 1953 171:737-738.

18. Lowdin PO: Proton Tunneling in DNA and its Biological Implications. Rev Mod Phys 1963, 35:724-732.

19. Noguera M, Sodupe M, Bertran J: Effects of protonation on protontransfer processes in guanine-cytosine Watson-Crick base pairs. Theor Chem Acc 2004, 112:318-326.

20. Bertran J, Blancafort L, Noguera M, Sodupe M: Proton transfer in DNA. Potential Mutagenic Processes. In Computational studies of RNA and DNA (Challenges and Advances in Computational Chemistry and Physics). Edited by: Sponer J, Lankas F. Springer; 2006:411-432.

21. Wang H, Zhang JD, Schaefer HF III: The Protonated Guanine-Cytosine Base Pair. ChemPhysChem 2010, 11:622-629.

22. Patel DJ, Bouaziz S, Kettani A, Wang Y: Structures of guanine-rich and cytosine-rich quadruplexes formed in vitro by telomeric, centromeric, and triplet repeat disease DNA sequences. In Oxford Handbook of Nucleic Acid Structure. Edited by: Neidle S. New York: Oxford University Press; 1999:389-453.

23. Johnson SL, Rumon KA: Infrared spectra of solid 1:1 pyridine-benzoic acid complexes; the nature of the hydrogen bond as a function of the acidbase levels in the complex. J Phys Chem 1965, 69:74-86.

24. Bhogala BR, Basavoju S, Nangia A: Tape and layer structures in cocrystals of some di- and tricarboxylic acids with 4, 4'-bipyridines and isonicotinamide. From binary to ternary cocrystals. CrystEngComm 2005, 7:551-562

25. Molčanov K, Kojić-Prodić B: Salts and co-crystals of chloranilic acid with organic bases: is it possible to predict a salt formation? CrystEngComm 2010, 12:925-939.

26. Peräkylä M: A Model Study of the Enzime-Catalyzed Cytosine Methylation Using ab Initio Mechanical and Density Functional Theory Calculations $\mathrm{pk}_{\mathrm{a}}$ of the Cytosine N3 in the Intermediates and Transition States of the Reaction. J Am Chem Soc 1998, 120:12895-12902.

27. Portalone G, Colapietro M: Solid-phase molecular recognition of cytosine based on proton-transfer reaction. J Chem Crystallogr 2009, 39:193-200.

28. Bondi A: van der Waals Volumes and Radii. J Phys Chem 1964, 68:441-451.

29. Goldman P: The Carbon-Fluoride Bond in Compounds of Biological Interest. Science 1969, 164:1123-1130.

30. Jeschke P: The Unique Role of Fluorine in the Design of Active Ingredients for Modern Crop Protection. ChemBioChem 2004, 5:570-589.

31. Böhm H-J, Banner D, Bendels S, Kansy M, Kuhn B, Müller K, Obst-Sander U, Stahl M: Fluorine in Medicinal Chemistry. ChemBioChem 2004, 5:637-643. 
32. Reichenbächer $\mathrm{K}$, Süss $\mathrm{Hl}$, Hulliger J: Fluorine in crystal engineering-"the little atom that could". Chem Soc Rev 2005, 34:22-30.

33. O'Hagan D: Understanding organofluorine chemistry. An introduction to the C-F bond. Chem Soc Rev 2008, 37:308-319.

34. Howard JAK, Hoy VJ, O'Hagan D, Smith GT: How Good is Fluorine as a Hydrogen Bond Acceptor? Tetrahedron 1996, 52:12613-12622.

35. Dunitz JD, Taylor R: Organic Fluorine Hardly Ever Accepts Hydrogen Bonds. Chem Eur J 1997, 3:89-98.

36. Dunitz JD: Organic Fluorine: Odd Man Out. ChemBioChem 2004, 5:614-621.

37. Frölich R, Rosen TC, Meyer OGJ, Rissanen K, Haufe G: New indications for the potential involvement of C-F bonds in hydrogen bonding. J Mol Struct 2006, 787:50-62.

38. Chopra D, Guru Row TN: Role of organic fluorine in crystal engineering. CrystEngComm 2011, 13:2175-2186.

39. Sarma B, Nath NK, Bhogala BR, Nangia A: Synthon Competition and Cooperation in Molecular Salts of Hydroxybenzoic Acids and Aminopyridines. Cryst Grow Des 2009, 9:1546-1557.

40. McClure RJ, Craven BM: New Investigation of Cytosine and Its Monohydrate. Acta Crystallogr Sect B 1973, 29:1234-1238.

41. Thomas R, Srinivasa Gopalan R, Kulkarni GU, Rao CNR: Hydrogen bonding patterns in the cocrystals of 5 -nitrouracil with several donor and acceptor molecules. Beilstein J Org Chem 2005, 1:15-25.

42. Hulme AT, Tocher DA: The Discovery of New Crystal Forms of 5Fluorocytosine Consistent with the Results of Computational Crystal Structure Prediction. Cryst Grow Des 2006, 6:481-487.

43. Kennedy AR, Okoth MO, Sheen DB, Sherwood JN, Vrcelj RM: Two New Structures of 5-Nitrouracil. Acta Crystallogr Sect C 1998, 54:547-550.

44. Oxford Diffraction, CrysAlis Software System: Oxford Diffraction Ltd., Xcalibur CCD System, Abingdon, Oxfordshire, UK; 2008, Version 1.171.32.29.

45. Farrugia LJ: WinGX Suite for small-molecule single-crystal crystallography. J Appl Crystallogr 1999, 32:837-838.

46. Burla MC, Camalli M, Carrozzini B, Cascarano GL, Giacovazzo G, Polidori G, Spagna R: SIR2002: the program. J App/ Crystallogr 2003, 36:1103.

47. Sheldrick GM: A short history of SHELX. Acta Crystallogr Sect A 2008, 64:112-122.

48. Spek AL: PLATON, A Multipurpose Crystallographic Tool. Utrecht University, Utrecht, The Netherlands; 1998.

49. Farrugia LJ: A ORTEP-3 for Windows - a version of ORTEP-III with a Graphical User Interface (GUI). J Appl Crystallogr 1997, 30:565.

doi:10.1186/1752-153X-5-51

Cite this article as: Portalone: Solid-phase molecular recognition of cytosine based on proton-transfer reaction. Part II. supramolecular architecture in the cocrystals of cytosine and its 5-Fluoroderivative with 5Nitrouracil. Chemistry Central Journal 2011 5:51.

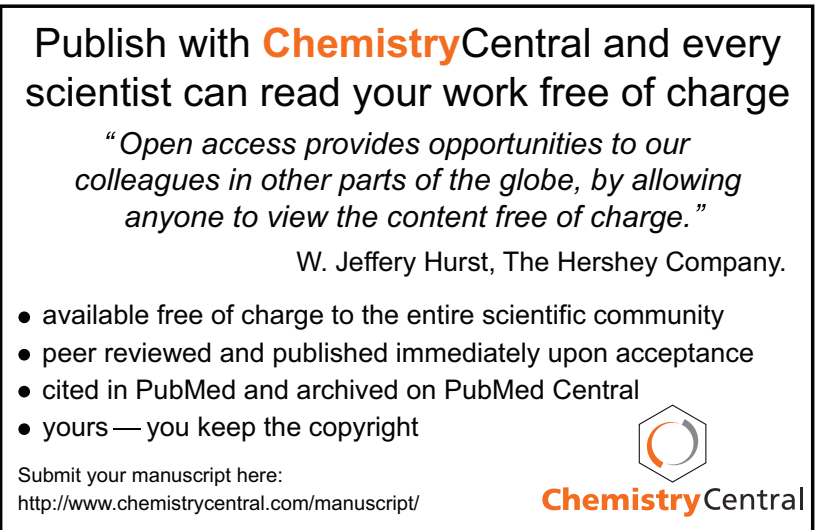

